\title{
A Teachers Perception on Localization of Curriculum with Emphasis on Social Studies Lesson
}

\author{
Shiva Jalayeri Laeen ${ }^{1}$, Mohsen Ayati ${ }^{2}$, Hossein Jafari Sani ${ }^{3}$ \& Mohammad Akbari Booreng ${ }^{4}$ \\ ${ }^{1} \mathrm{Ph} . \mathrm{D}$. Student in Curriculum Studies, Educational Science Department, University of Birjand. \\ ${ }^{2}$ Associate Professor, Educational Science Department, University of Birjand. \\ ${ }^{3}$ Associate Professor, Curriculum Studies Department, Ferdowsi University of Mashhad (FUM). \\ ${ }^{4}$ Assistant Professor of Curriculum Studies, Educational Science Department, University of Birjand. \\ Correspondence: Mohsen Ayati, Associate Professor, Educational Science Department, University of Birjand. E-mail: \\ mayati@birjand.ac.ir
}

Received: July 17, 2019

Accepted: October 10, 2019

Online Published: October 28, 2019

doi:10.5430/ijhe.v8n7p84

URL: https://doi.org/10.5430/ijhe.v8n7p84

\begin{abstract}
The aim of this study understands teacher perceptions of the localization of curriculum of primary school. on the social Study Lessons. The methodological approach of this study is to investigate phenomenology as a qualitative method. The potential contributors were the native teachers of the Kalat city (Laeenno) in the 1397 which 19 participant were selected. Data were collected using face-to-face interviews and were analyzed by Glaserian seven phases. Reliability was achieved through three criteria: being acceptable, being trustful and verifiability. The findings show that the current performance of students end up in lack of incentive, leaving school, shallow learning, the inefficiency of current performance of teachers, interruptions in communication, One-way interaction, and the challenges of localization is denial of the cultural diversity of politicians, non-native content (centralized knowledge), Lack of in-service courses, the time challenge, recruiting non-native teachers, the lack of comprehensive studies of sub-cultivated areas, immigration, executive challenge, School space and lack of a template from native syllables, and the consequences of localization for teachers is contentment of teaching, Creating and improving communication and promoting native culture, and the consequences of localizing for students is: protecting from native culture, Creating a motivation to learn and absorb and stay in the classroom and school. Finally, teachers' strategies about localization of Klein's nine elements in the curriculum of social studies were identified.
\end{abstract}

Keywords: phenomenology, lived experienced, teachers, localization of curriculum, social studies

\section{Introduction}

Globalization is a key concept in human rights, however, some researchers have challenged this concept. These criticisms remind us of the asymmetric power relations and the point that human rights, cultural diversity, justice, and injustice should be considered in the curriculum (Osler, 2015). Australia, Canada and the United States (Alismail, 2016; Muchenje \& Heeralal, 2016), Taiwan (Wang \& Ho, 2012), China (Jiafang, 2013; Daishu, 2009), Turkey (Cirik, 2014), South Korea (Denis, 2011) and Norway (Sarraj, Bene \& Burley, 2015) are trying to help these challenges by strengthening national and local concepts. Localization demands the dissemination, adaptation and growth of the paradigm of knowledge, technology, behavioral norms, cultural and local values in a specific situation and a response to the phenomenon of globalization (Moradipour, 2017). Location-based curriculum designing investigates how local region capacities and resources are used as the motivator and source of inspiration of curriculum, and seeks the methods of making meaningful learning experiences more enriched in the geography, history, culture, and individuals in their local region. In the local curriculum, elements are organized on the basis of local culture identities and activities are predicted to realize these goals (Mulla and Adib, 2017). The local curriculum considers developing students' skills, knowledge, abilities, and attitudes in a meaningful and relevant context (Haji Tabar Firouzajaie \& Mir Arab Razi, 2017).

Theories by Cheng (2004) show what policy the educational systems can adopt in relation to localization. In Tree Theory, knowledge is rooted in local values and traditions (Shekari and Mazdaie, 2009). In Crystal Theory (Haji Tabar Firouzajaie \& Mir Arab Razi, 2017), the design of national and local curricula is related and aligned with the global knowledge (Cheng, 2000). In the Theory of Birdcage (Moradipour, 2017), traditions and local elements should be placed as the bases in the training principles (Nasrabadi et al., 2013). In the Theory of Fungus China (Jiafang, 2013; 
Daishu, 2009), Turkey (Cirik, 2014), global knowledge must remove the needs of local people. Finally, according to the Theory of Amoeba Mulla and Adib, 2017), the growth and development of local knowledge depends on the useful use of global knowledge (Qassempour Dehaghani, Jafari, and Liaghatdar, 2011). In addition to the Cheng's theories (2004), Lave and Wenger's Situational Learning Theory (1991), Vygotsky's Cultural Theory (1978), Bruner's Theory of Learning Culture (1996), Dewey's Self-Life Education (1897), Kolb's Experiential Learning (1984), and Freire's Human Education (1970) can be a guide for theoretical discussions about the localization of curricula. In addition, the most recent theories supporting localization include neo-conceptualists Mulla and Adib, 2017), postmodernists Mulla and Adib, 2017), neo-idealists Mulla and Adib, 2017), cultural pluralists ,that each one in a way has a particular emphasis on the rights of minorities and the culture (Sharif, 2011; Ghaderi, 2008; ALKAN \& ALTUNDAĞ, 2016).

Evidence shows that the localization of curricula makes students' academic progress and individual development Mulla and Adib, 2017). In the research of Tulgar (2018), the interaction between teachers' education and its coordination with the mother tongue and intercultural interactions to preserve learners' local culture have been emphasized. Alismail (2016) believed that culture-based education promotes and improves learning and develops students' cultural perspective. According to Demir and Yurdakul (2015), culture-based programs reduced racial and cultural prejudices. Spindler (1987) stated that, teaching and learning are cultural processes that occur in the social context. In order to able to provide maximum qualitative education to various students, their culture must clearly be understood (Banks \& Banks, 2005). In explaining the necessity of localizing the curricula, the existence of various subcultures in Iran should be mentioned. The simultaneous presence of various ethnic groups in a single land is defined as the multiethnic community (Parekh, 2008).

Moreover, the necessity of compiling local programs can also be investigated and explained from the perspective of the Qur'an, documents and high-level laws. In verse 22 of Chapter Rome it says: "One of the signs of the power of God is creation of the heavens and the earth, and also the difference of languages and colors of men". Article 19 of the Constitution refers to the ethnic and racial equality, and Article 15 refers to considering local and ethnic languages (Articles of the Constitution, 2011). In addition, the Development Perspective Document has proposed the issue of paying attention to "preserving human dignity and rights" "creating equal and non-discriminatory opportunities", "social justice and legitimate freedoms" as a part of its goals. The Supreme Council of the Cultural Revolution has also mandated Education and Training to insert a summary of the history of Islamic and Iranian culture and civilization in the textbooks. On the other hand, The philosophy of formal and public education of the Islamic Republic of Iran has taken into consideration the principle of diversity, pluralism and educational justice as a part of the principles governing formal education (Sadeghi, 2012). This issue area? has also been considered in the national curriculum Mulla and Adib, 2017). Curricula should provide the context of strengthening national identity by emphasizing cultural values and linguistic and cultural differences (National Curriculum Document, 2012). The Articles 6 and 7 of the Universal Declaration of the Human Rights explicitly recognizes and protects minorities and their culture and declares that students with their life experience enter the school, so their cultural rights can be respected (Osler, 2015).

Curriculum requires the participation of all influential forces in various stages of decision making, among which teachers due to having familiarity with the students' issues and needs, have a special position and importance (Shawer, 2017). Research by Alismail's (2016), Hong, Chang \& Yang (2017), Apple and Smith (2007), Muchenje, F., \& Heeralal (2016) and Shawer (2017) outline the importance of teacher's role in curriculum designing. In addition, in Iran, the research conducted by Hajitabar Firojaie and Mir Arab Razi (2016); Sadeghi, Abdolmaleki and Khoda Rahmi (2016); Fahimi and Sheikhzadeh (2013); and Mohammadi, Shirkouh, Kharrazi, Naghikamal, Kazemi Fard and Pourkarim (2016) have investigated the localization of the curriculum according to the teachers' view. McCarthy and Stanton's (2017 research stated that the community's response to incorporating a local discourse into the region's curriculum and preserving local culture in Indian curricula was required.

The planned curriculum should reflect the culture of the people. Each curriculum is based on culture, generalizations, specialties, and cultural alternatives. These have all been chosen in the curriculum. The headlines of applied curricula are a reflection of culture. Therefore, culture should be applied into the curriculum and curriculum headlines in an integrative way. The curriculum is a real tool to help preserving and acquiring the cultural achievements of a nation (Afforma, 2016). Each of the subcultures has specific religious, linguistic, belief traditions, and different residential place and distinguishes them from other cultures. Schools have roles for the community culture, and in this respect the social studies curriculum has a more important and effective role (Muchenje, F., \& Heeralal, 2016). In Turkey, 85 of the 175 goals are related to local goals, including the social studies course (Cirik, 2014). In this regard, the goals of the social studies education program have been determined by the Ministry of Education and Training of Turkey? in a number of domains. Concerning in the cognitive domain, the goals that are related solely to the student's mental activities are considered. In the skill domain, goals that are related to the skills and practical abilities are considered, 
and in the value domain, the goals that have emotional aspect and show individuals' social attitudes and mindsets are expected. It should be said that dividing the goals into triple domains has face value aspect and is performed to facilitate the lesson planning and there is no clear boundary between them (Kazempour \& Ghaffari, 2009). Research of Hamidizadeh, Fathi Vajjargah, Arefi and Mehran (2017) stated that social studies can help localizing the curriculum by proposing culture-related topics. However, the results of Razaghi's research (2013) showed that the Iranian education system lacks a proper model and solution in respect of local curriculum, since teachers are the executors of the curricula and can help removing the problems of compiled future programs; hence, investigating their experience can clarify the challenges, solutions, and consequences of localization in the elementary level textbooks. Therefore, considering the importance of this topic in the high-level documents, the existence of cultural diversity in Iran, and the emphasis of domestic and foreign research on the necessity of localizing the curriculum, the purpose of the present research is to analyze the teachers' experiences of Kalat about what, why and how to localize and the localization solutions of the course of social studies in the elementary level. The following questions guided the research design:

What is the impact of non-local content on students?

What is the impact of non-local content on teachers?

What challenges the localization of curricula is associated with according to the teachers' viewpoint?

What consequences does the localization of curricula have for teachers?

What consequences does the localization of curricula have for students according to the teachers' viewpoint?

What are the solutions for the localization of social studies course curriculum according to the teachers' viewpoint?

\section{Research Methodology}

The purpose of the present research is to understand teachers' perception about the localization of the curriculum. Through a qualitative, phenomenological methodology Mulla and Adib, 2017), the intellectual categories of the research group were considered to describe their attitude and behaviors (Strauss and Corbin, 2011).

The participants of research were all local teachers of Kalat from the first to sixth grade with at least 10 years of experience. By using a purposeful sampling method (Gall, Borg \& Gall, 2013)., 19 teachers were selected. In the purposeful sampling method, interviewing continues until the theoretical saturation stage, when the responses of new sample are the same kind as previous responses and no new information and solution are produced Further explanation as to why this was done, with specific reference to the research (Gall, Borg \& Gall, 2013; Kasteyeva, 2018).

The data collection tool used was a semi-structured interview Most interviews were conducted outside the school hours in an informal setting. The time of interviews was conducted beforehand in coordination with the interviewee. At the beginning of each interview, the researcher explained about how the interview was conducted and the purpose of the research and ensured the confidentiality of the information. The interview process began with proposing the research question and explaining and stating the importance and necessity, and then proposing the interview questions began. The interviewees were initially asked a general and open question, but the next questions were designed in a way to help the research purpose, that is, broad questions related to the research question were proposed and some questions were also formed during the interview. At the beginning of the interview, as the subject is the localization of the curriculum, in order to motivate and attract interviewees' attention some questions were asked regarding the culture and attractions related to the local culture and their interest and feeling towards local culture, and then the discussion continued to the way that how the local culture can be preserved in their opinion and what are the solutions for preserving local culture and then they were asked to state their opinion about the challenges, consequences, and how to localize the curriculum.

For validation and reliability, three criteria considered by qualitative studies experts, including acceptability, reliability and validity were used (Mansourian, 2012; Fujo \& Dida, 2019). In order to be acceptable and to confirm the accuracy of findings, transcripts of the interview and the research report were sent to the teachers to specify the agreement of the mentioned points and the research findings. To ensure the reliability of the findings, it was tried to clearly describe the processes and decisions related to the research in the research text. For the conformity of the results, the findings were compared with the literature review and by referring to the theoretical discussions they were explained (Matandare, 2018).

The analysis of findings was performed based on the Colaizzi's seven-step method (Sanders, 2003). The process of data analysis was performed regarding the nature of the research subject and it was reciprocal. In the way that after each step of data collection the process of analyzing and coding it began, but the basic and systematic action to analyze the data began when all the obtained data was collected and implemented. 


\section{Findings}

The research findings in the form of extracted concepts have been reported by mentioning evidence according to the interviewees' opinion, that ultimately, in the final question regarding the importance of the subject of social studies course, these concepts have been explained in detail in Klein's nine elements.

The First Question: What is the impact of non-local content on students?

The concepts extracted from the interviews in this main field have three sub-conceptual codes as follows. Lack of Motivation: Teachers believe that students lack motivation to learn concepts completely unrelated to their local culture. Dropout: Teachers acknowledge that the ratio of elementary school dropout in this region is high. Superficial Learning: Teachers believe that the knowledge students learn is superficial and it does not link them to their previous learning.

The Second Question: What is the impact of non-local content on teachers?

The concepts extracted from the interviews in this main field have three sub-conceptual codes as follows. Inefficient Teaching: Teachers acknowledge that they are not completely successful in teaching the current content. Communication Disorder: Teachers believe that in teaching the current content the communication between teacher and student is one-way; however, communication is bilateral when local examples are used; but, we must teach the content existing in the books. These goings and returns cause a conflict in the communication of teacher and student. One-Way Interaction: Teachers acknowledge that as we are aware of the content of the book, and the students do not know about it, this factor makes one-way interaction between us.

The Third Question: What challenges the localization of curriculum is associated with according to the teachers' viewpoint?

The concepts extracted from the interviews in this main field have ten sub-conceptual codes as follows. Not Accepting the Cultural Diversity Domain by Policy Makers: Teachers believe that understanding policy makers and educational planners about the issue of cultural diversity is the first thing to do to begin localizing curricula. Non-Local Content (Concentrated Knowledge): Teachers know the sovereignty of national content in books as a challenge for localization. The Lack of In-Service Courses: Teachers consider the lack of in-service courses a challenge for localization. Time Challenge: For teachers, the shortage of time to teach is a challenge to localize curricula. Non-Local Teachers' Recruitment: Teachers acknowledge that the use of non-local teachers in multicultural schools is a challenge to the localization of curricula. Lack of Comprehensive Studies about Regions with Subcultures: Teachers' experiences indicate that comprehensive studies have not been conducted about ethnicity groups to perform localization based on the characteristics and needs of ethnicities. Migration: Teacher and students' relocations create problems for localization. Executive Challenge: Teachers have declared the lack of facilities, resistance of teachers unaware of the local culture, the lack of sufficient budget, the absence of orthography for writing local language, the use of non-local teachers in this region, not collaborating with officials and designers among the executive challenges of localization. School Space: If programs are localized, basic changes should be created in the physical environment of schools. This point requires coordination of all relevant factors. Absence of a Local Curriculum Model: Teachers acknowledge that they have an important role in designing local programs, and consider the absence of an example of local program a challenge.

The Fourth Question: What consequences does the localization of curriculum have for teachers?

The concepts extracted from the interviews in this main field have three sub-conceptual codes as follows. Satisfaction Feeling with Teaching: Teachers have a good sense when teaching their local culture. Creating and Improving Communication: Teachers acknowledge that local content improves communication between teacher and students. Promoting and Preserving Local Culture: Most teachers consider preserving, promoting and transferring their local culture a duty.

The Fifth Question: What consequences does the localization of curriculum have for students according to the teachers' viewpoint?

The concepts extracted from the interviews in this main field have three sub-conceptual codes as follows. Preserving Students' Local Culture: Teachers believe that the students of this region are very interested in their customs and traditions. Here is the last zero-boundary point to defend the culture that the localization helps this effort. Creating Motivation for Learning: Teachers acknowledge that content related to the context of students' life enhances their motivation to learn. Attraction and Retention in the Classroom and School: According to the teachers the localization of curricula helps students' attraction and retention at school.

The Sixth Question: What are the solutions for the localization of social studies curriculum according to the teachers' viewpoint?

The concepts extracted from the interviews in this field have been derived in the form of Klein's nine elements (goal, 
content, teaching-learning strategies, grouping, materials and resources, space specifications, time status, learning experiences, and evaluation). Sub-conceptual codes have been extracted and reported for each one of these elements.

Table 1. The Solutions to Localize the Curriculum in the Form of Klein's Nine Elements

\begin{tabular}{|c|c|c|}
\hline Major Themes & Minor Themes & Primary Themes \\
\hline Goal & $\begin{array}{l}\text { - Strengthening students' national identity } \\
\text { - Helping students' local culture preservation } \\
\text { and developing their knowledge } \\
\text { - Preventing discrimination and differences } \\
\text { - Making student interested and attracted to } \\
\text { the school } \\
\text { - Helping decentralization of curricula and } \\
\text { preventing content being uniform } \\
\text { - Helping students' cognitive growth through } \\
\text { studying local content } \\
\text { - Helping emotional growth }\end{array}$ & $\begin{array}{l}\text { It will lead to preserving local culture and creating } \\
\text { interest in students' national identity - strengthens } \\
\text { interest in preserving local culture among students - } \\
\text { makes Kurd students to have self-value feeling in } \\
\text { this region- by seeing their culture in the book they } \\
\text { become more interested - it prevents cultural } \\
\text { uniformity- bringing objective examples strengthens } \\
\text { mental growth- students enjoy more when I use } \\
\text { examples of their real environment }\end{array}$ \\
\hline Content & $\begin{array}{l}\text { - Content components } \\
\text { - Organizing content }\end{array}$ & $\begin{array}{l}\text { Social customs and traditions of the region - } \\
\text { introducing handicrafts - using local signs- } \\
\text { agricultural products - introducing wildlife and local } \\
\text { integrated-separate geography }\end{array}$ \\
\hline $\begin{array}{l}\text { Teaching- } \\
\text { Learning } \\
\text { Strategies }\end{array}$ & $\begin{array}{l}\text {-Teaching methods } \\
\text { - How to teach }\end{array}$ & $\begin{array}{c}\text { General - Specific; teaching by local teacher and } \\
\text { non-local assistant teacher- Getting help from local } \\
\text { forces- Designing local networks }\end{array}$ \\
\hline Grouping & $\begin{array}{l}\text { - Forming homogeneous groups } \\
\text { - Forming heterogeneous groups }\end{array}$ & $\begin{array}{l}\text { Forming homogeneous groups separately (Kurd), } \\
\text { (Turk), (Tat), (Balouch), (Berber) - Forming diverse } \\
\text { linguistic and cultural groups in one group (Kurd, } \\
\text { Turk, Balouch, Tat, Berber, Lak) }\end{array}$ \\
\hline $\begin{array}{l}\text { Materials and } \\
\text { Resources }\end{array}$ & $\begin{array}{l}\text { - Public resources } \\
\text { - Local resources }\end{array}$ & $\begin{array}{l}\text { Maps, sphere, charts, book, tuition help, pictures, } \\
\text { booklets, local books, historical atlases, historical } \\
\text { CDs, local maps, informed people and experts, } \\
\text { natural environment, local workshops }\end{array}$ \\
\hline $\begin{array}{c}\text { Space } \\
\text { Specifications }\end{array}$ & $\begin{array}{l}\text { - Physical space } \\
\text { - Emotional space }\end{array}$ & $\begin{array}{l}\text { Using the speech of well known local people on the } \\
\text { door, wall and hallway. Using various and happy } \\
\text { colors in the classroom and at school space. Using } \\
\text { photo and poster about successful local men and } \\
\text { women - Designing a positive emotional space. } \\
\text { Creating intimate space for the interaction of } \\
\text { existing subcultures. Designing class spaces for } \\
\text { interaction and creating intimate communication } \\
\text { between teacher and students }\end{array}$ \\
\hline Time Status & $\begin{array}{l}\text { - Increasing current prescription time } \\
\text { - Designing informal times }\end{array}$ & $\begin{array}{l}\text { The current time is also good to teach the local } \\
\text { curriculum, but it is better if they increase the time - } \\
\text { in the local curriculum along with the national } \\
\text { program more time should be allocated to attend } \\
\text { local rituals and ceremonies and visiting the } \\
\text { spectacular places of village and productive centers. }\end{array}$ \\
\hline $\begin{array}{l}\text { Learning } \\
\text { Experiences }\end{array}$ & $\begin{array}{l}\text { - Practical activities } \\
\text { - Executive activities }\end{array}$ & $\begin{array}{c}\text { Students can do a variety of activities, such as } \\
\text { making a black tent together or draw a replica of the } \\
\text { village - taking them to related centers to see local } \\
\text { art such as needle working or carpet weaving and } \\
\text { jajim weaving. }\end{array}$ \\
\hline Evaluation & $\begin{array}{l}\text { - Investigating folder } \\
\text { - Investigating practical assignments } \\
\text { - Investigating normal performance }\end{array}$ & $\begin{array}{l}\text { To evaluate students' learning, they investigate their } \\
\text { folders - observing that students objectively respect } \\
\text { adults; in fact, evaluation has a functional state } \\
\text { more. }\end{array}$ \\
\hline
\end{tabular}




\section{Analysis of Teachers' Perception for Extracting "Goal" in the Local Curriculum}

Local teachers' perception in respect of extracting the element of "goal" in the local curriculum was analyzed that in this element in the local curriculum of social studies course, the following concepts are extracted from the teachers' perception: 1- Strengthening students' national identity, 2- Helping students' local culture preservation and developing their knowledge, 3-Preventing discrimination and differences, 4- Making student interested in and attracted to the school, 5- Helping decentralization of curricula and preventing content being uniform, 6- Helping students' cognitive growth through studying local content, and 7- Helping emotional growth.

\section{Analysis of Teachers' Perception for Extracting "Content" in the Local Curriculum}

Local teachers' perception in respect of extracting the element of "content" in the local curriculum was analyzed that in this element in the local curriculum of social studies course, the following concepts are extracted from the teachers' perception. These concepts can be proposed into two parts of content components, organizing content:

A: Contents Components that Can Be Proposed in the Local Curriculum of Social Studies: 1- Social customs and traditions of the region, 2 - Introducing handicrafts, 3 - Using local signs in the content (Kurdish names, local music, and local foods), 4- Agricultural products, local dairy, 5- Introducing wildlife and local geography, and 6-Introducing historical locations.

B: Organizing Content: Organizing content is divided into two integrated and separate sections each with its specific own sub-concepts. 1) Integration: 1- Organizing local content alongside global and national content, 2- Organizing local content alongside current content, 2) Separate: 1- Designing a local curriculum in a separate booklet, 2Attachment of local curriculum content at the end of the book, 3- Attachment of local curriculum content at the end of each chapter.

\section{Analysis of Teachers' Perception for Extracting "'Teaching-Learning Strategies" in the Local Curriculum}

Local teachers' perception in respect of extracting the element of "teaching-learning strategies" in the local curriculum was analyzed, that in this element in the local curriculum, the social studies course is in the form of two parts of teaching methods and how to teach; the following concepts are extracted from teachers' perception: A. Teaching Methodology: 1. General methods. 2. Specific methods. B: How to Teach: 1- Teaching by a local teacher and a non-local assistant teacher, 2- Getting help from local forces, 3- Designing local networks to use local networks.

\section{Analysis of Teachers' Perception for Extracting "Grouping" in the Local Curriculum}

Local teachers' perception in respect of extracting the element of "grouping" in the local curriculum was analyzed that in this element in the local curriculum, the social studies course is in the form of two parts of the formation of homogeneous groups and the formation of heterogeneous groups; the following concepts are extracted from teachers' perception: A. Forming Homogeneous Groups: Forming homogeneous groups separately (Kurd), (Turk), (Tat), (Balouch), (Berber), B) Forming Heterogeneous Groups: Forming diverse linguistic and cultural groups in one group (Kurd, Turk, Balouch, Tat, Berber, and Lak).

\section{Analysis of Teachers' Perception for Extracting "Materials and Resources" in the Local Curriculum}

Local teachers' perception in respect of extracting the element of "materials and resources" in the local curriculum was analyzed that in this element in the local curriculum, the social studies course is in the form of two parts of public resources and local resources; the following concepts are extracted from the teachers' perception: A: Public Resources: Maps, sphere, charts, book, tuition help, pictures, booklets. B: Local Resources: According to the perspective of one of the local teachers of the region: local books, historical atlases, historical CDs, local maps, informed people and experts, natural environment, local workshops, ecosystem of the region, historical locations of the region, cultural monographs of the region, local people's memories, narrations, local tales, local encyclopedias, local dictionaries, parents' experiences, local poems, local firsthand resources, and local proverbs.

\section{Analysis of Teachers' Perception for Extracting Space Specifications" in the Local Curriculum}

Local teachers' perception in respect of extracting the element of "space specifications" in the local curriculum was analyzed that in this element in the local curriculum, the social studies course is in the form of two parts of physical space and emotional space; the following concepts are extracted from the teachers' perception: A. Physical Space: 1Using the speech of well known local people on the door, wall and hallway, 2- Using various and happy colors in the classroom and at school space, 3- Using photo and poster about successful local men and women, 4- Using photo and poster appropriate to the season of migration, planting and harvesting and other important ceremonies of the region. B: Emotional Space: 1- Designing a positive emotional space, 2- Creating intimate space for the interaction of existing subcultures, 3- Designing class spaces for interaction and creating intimate communication between teacher and students, 4- Designing a happy and varied space in the classroom by the aid of local resources, 5- Enjoying from local 
music and sounds and songs in national festivals and ceremonies to stylize students' morale, 6- Holding local festivals and conferences to pay attention to the students' emotion and raising students' taste.

\section{Analysis of Teachers' Perception for Extracting "Time Status" in the Local Curriculum}

Local teachers' perception in respect of extracting the element of "time status" in the local curriculum was analyzed that in this element in the local curriculum of the social studies course; the following concepts are extracted from the teachers' perception: 1- Increasing the current prescriptive time 2- Designing informal times (non-prescriptive).

\section{Analysis of Teachers' Perception for Extracting "Learning Experiences" in the Local Curriculum}

Local teachers' perception in respect of extracting the element of "learning experiences" in the local curriculum was analyzed that in this element in the local curriculum, the social studies course is in the form of two parts of scientific activities and executive activities; the following concepts are extracted from the teachers' perception, A: Practical Activities: 1. Making and painting and drawing handicrafts and crafts and visual arts, 2- Writing and drawing, 3Holding local competitions and cooking local foods, 4- Building theater and competitions with local content for important days, B: Executive Activities: 1- Visiting artistic, production centers and workshops and writing report, 2Identifying and naming historical regions, 3-Classification of the medical herbals of the region, 4- Identifying local animals of the region, 5- Preparing a wall newspaper with local culture topics, 6- Interviewing local people about local issues, 7- Making videos from local celebrations and rituals.

\section{Analysis of Teachers' Perception for Extracting "Evaluation" in the Local Curriculum}

Local teachers' perception in respect of extracting the element of "evaluation" in the local curriculum was analyzed that in this element in the local curriculum of the social studies course, the following concepts are extracted from the teachers' perception, 1- Investigating folder, 2- Investigating practical assignments, 3- Investigating normal performance.

According to the research findings, the network of curriculum localization themes has been presented in Figure

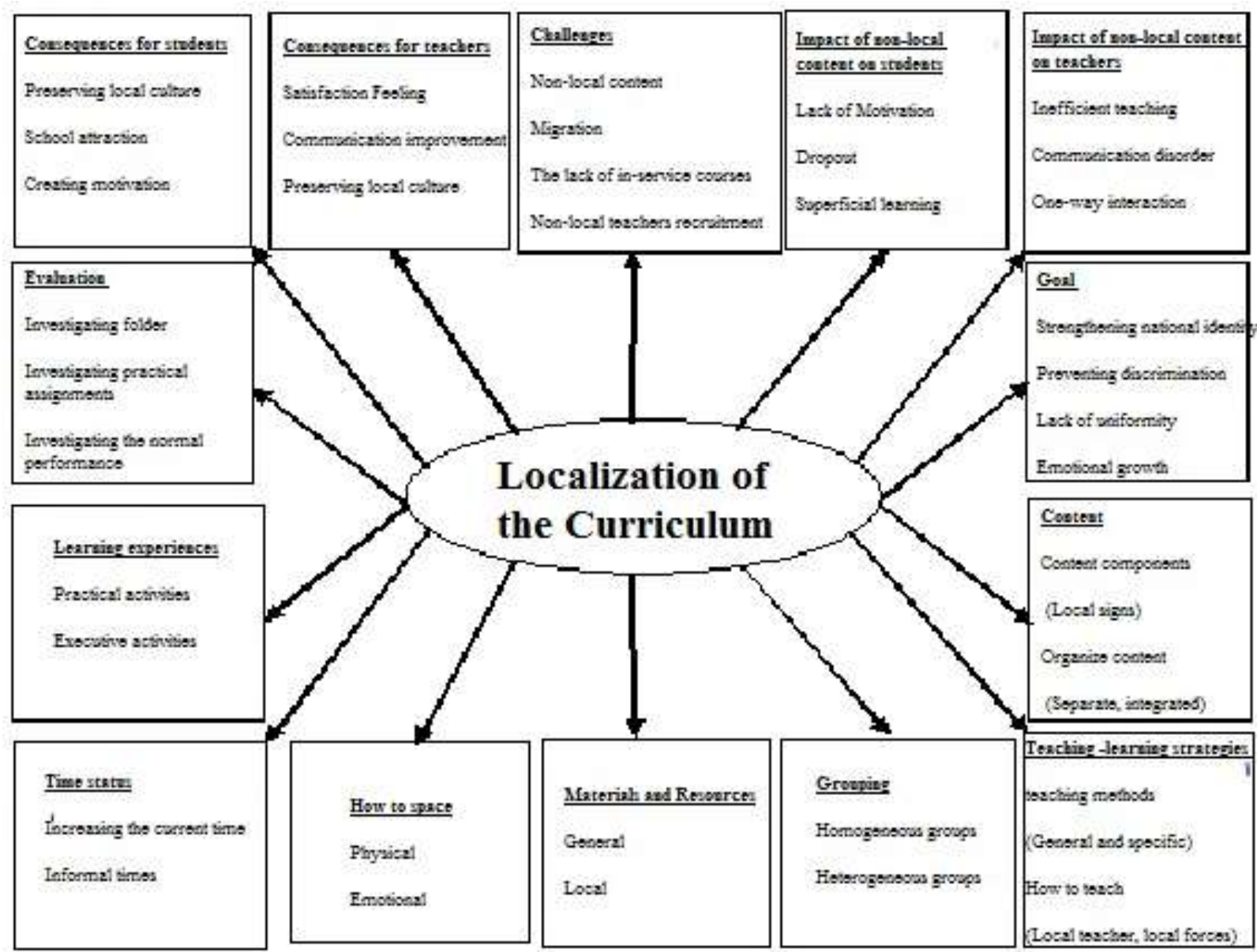

Figure 1. Localization of the Curriculum 


\section{Discussion and Conclusion}

Various cultures have different norms, values and expectations, and these cultural differences have a profound effect on educational activities. The cultural trends and the values of each culture have been effective on how the process of teaching and learning of learners is and form the teachers' attitudes towards educational activities; therefore, the teaching-learning process in each culture differs according to the perceptions and conceptions of its main actors. The research was conducted with the main aim of investigating the phenomenology of teachers about the nature, consequences, challenges and solutions of the localization of curricula with special emphasis and look at the social studies course.

Localization of curriculum in addition to requiring principled designing and organizing, in the next stage requires teachers to be able to implement it, so teachers' understanding and recognition of the local curriculum is very important, as Alismail's (2016) reported how teacher's understanding of the localization of programs develops and changes their perspective in implementing local curriculum.

Employing non-local teachers can also be a barrier to the localization. Research by Denis (2011) found that local teachers have more commitment to understand and transmit local culture and are more successful in these programs. In a study by Sianturi, Chiang and Au Hurit (2018), local teachers are needed for teaching local curricula for local students.

How to design the school space can also be an obstacle for localization. In this respect, it was mentioned in the research of Osler (2015) that in the local curricula, educational buildings, facilities, and space appropriate to the culture of ethnicities should be designed. The role of school is to consider the ethnic attitudes and values in a democratic society and to create a safe and acceptable environment and to encourage learners for critical thinking, and to prevent discrimination between learners (Aydin, 2013).

Solutions for the localization of social studies curriculum can be investigated in Klein's nine elements:

Element of Goal: Among the goals of localizing the social studies curriculum can be respecting diverse local traditions by students (Putnam, Putnam, Jerome \& Jerome, 2011; Ramirez \& Jaffee, 2016).

Element of Content: In the context of local curriculum content, the following cases can also be mentioned: In the context of the content element, traditions, rituals, beliefs and values of local culture can be in the books, including social studies as content (Putnam et al., 2011), organizing local language, local traditions and customs taken from local culture (Tulgar, 2018), local knowledge such as local mathematics (Khakbaz, 2017), selecting local curriculum content with emphasis on knowledge related to the local culture (Misko, 2018), integrating local experiences with national and global experiences such as history, geography, cultural values in the textbooks (Allen, Jackson \& Knight, 2012), beliefs, historical knowledge and local geography: content in local programs including values, beliefs, historical and geographical knowledge can be designed in social studies books, and in the curriculum of language, art, and literature book (Aydin, 2013).

Element of Teaching-Learning Strategies: In the local curriculum, in the teaching topic the examples and samples can be used that are tangible for learners and they have felt their examples in their cultural context (Mohammadi et al., 2016).

Element of Grouping: In the local curriculum of social studies, in the grouping topic we can have the homogeneous and heterogeneous groups. Forming heterogeneous groups: In places where cultural heterogeneity exists, the formation of heterogeneous teams in the culturally responsive curricula becomes necessary (Jacob, Sabzalian, Jansen, Tobin, Vincent, LaChance, 2018). From the perspective of Demir and Yurdakul (2015), in the local programs the formation of team between heterogeneous groups is also effective in learning and reducing intergroup tensions. Homogeneous groups: in culturally responsive (local, indigenous) curricula.

Element of Materials and Resources: In the topic of materials and resources in the local curriculum of social studies, numerous resources can also be used. Applying local forces as resources: family interactions are important in the learning process. Elderly participation is essential because it is maintained through the elderly, traditions, culture, and language and values (Putnam et al., 2011). Using local poems and stories and tales: There are a variety of resources in cultural curricula, for example, resources can be the use of local poems, music and stories (Osler, 2015).

Element of Space Specifications: In the element of space in the local curriculum, the design of physical and emotional spaces can be organized according to the culture of each location. Attention of schools and educational community based on different ethnic and cultural characteristics: To preserve the rights of local people, buildings and school 
spaces should correspond with multicultural characteristics. The correspondence of the physical and educational spaces of schools with the characteristics of subcultures in cultural programs is important (Osler, 2016).

Element of Time Status: Teachers believe that the ratio of time allocated to a local curriculum of social studies should be increased and they require informal and non-prescriptive time programs for better implementation. In the research of Hamidizadeh et al. (2017), time limitation is also one of the factors affecting the design and implementation of multicultural programs.

Element of Learning Experiences: Visiting art and production centers and workshops and writing report. Identifying and naming the historic sites of the region and preparing poster, classifying the region's medical herbals, identifying local animals of the region, producing a wall paper with local culture topics, interviewing local people about local subjects, preparing video from local celebrations and rituals can be placed in the students' experiences discussion (Yuan, 2018).

Element of Evaluation: The evaluation process in local programs should be flexible and broad and should be performed based on the observation of student's behavior and performance in the cultural contexts, because the development of some attitudes can take a long time. Evaluation should reflect cultural diversity and should be appropriate for learners' cultural contexts (Demir and Yurdakul, 2015).

In many countries, with particular consideration and importance that the issue of subcultures and local and indigenous culture of minorities has, on the contrary they have not presented solutions to design local curricula; while, many researches and findings have explained the consequences of localization for students and teachers and in general for a nation and have warned the consequences of ignoring the topics of the localization of curricula and marginalizing the subcultures of a multiethnic community.There are many challenges and obstacles on the way of designing such programs that these obstacles require comprehensive investigation based on the culture of each country; challenges that their origin is the politicians' lack of understanding and accepting the need for the localization in curricula in communities with cultural diversity. There are other challenges as well, such as the lack of proper local curriculum design models or the challenges related to the implementation, and so on, that all of these cases should be considered in implementing a successful curriculum. It goes without saying that many countries with cultural diversity have taken steps in this regard and have considered local curricula, location-based and cultural programs.

Generally, according to the obtained results of this research it can be claimed that the living experiences of teachers in this research clarified many challenges and barriers, consequences, and how to localize the curricula, the results of which could be useful for other studies. Based on the obtained findings from this research, it is suggested to conduct study and research about multicultural regions and with subcultures in Iran. Investigating the challenges and barriers for the localization of curricula and how to remove these barriers, study and research about how to prepare the necessary infrastructures for localizing curricula, and designing and compiling a local curriculum model in various courses can be among the suggested cases of researches.

\section{References}

Alismail, H. A. (2016). Multicultural Education: Teachers' Perceptions and Preparation. Journal of Education and Practice, 7(11), 139-146.

ALKAN, F. \& ALTUNDAĞ, C. K. (2016). The Role of Technology in Science Teaching Activities: Web Based Teaching Applications. Journal for the Education of Gifted Young Scientists, 3(2), 1-7.

Allen, K. M., Jackson, I. \& Knight, M. G. (2012). Complicating Culturally Relevant Pedagogy: Unpacking African Immigrants' Cultural Identities. International Journal of Multicultural Education, 14(2), 1-27.

Aydin, H. (2013). a literature-based approach on multicultural education. The Anthropologist, 16(1-2), 31-44.

Banks, J. A. \& Banks, C. A. M. (2005). Multicultural education Issues and Perspectives (5th Ed.), New York: John Wiley.

Bruner, J. (1996). the culture of Education, Harvard University.

Cheng, Y. C. (2000). A CMI-triplization Paradigm for Reforming Education in the New Millennium. International Journal of Educational Management, 14(4), 156-174.

Cirik, I. (2014). Investigation of the relations between objectives of Turkish primary school curriculums and multiculturalism. Procedia-Social and Behavioral Sciences, 116, 74-76.

Demir, N. \& Yurdakul, B. (2015). the examination of the required multicultural education characteristics in curriculum design. Procedia-Social and Behavioral Sciences, 174, 3651-3655. 
Denis, V. (2011). Silencing Aboriginal curricular content and perspectives through multiculturalism: There are other children here. Review of education, pedagogy, and cultural studies, 33(4), 306-317.

Freire, P. (1970). Pedagogy of the oppressed, Penguin books.

Fujo, M. H. \& Dida, M. A. (2019). Centralized Admission System for Advanced Level Private Schools: Case of Kilimanjaro Region, Tanzania. Journal of Information Systems Engineering \& Management, 4(1).

Fahimi, Sedigheh \& Sheikhzadeh, Mustafa (2013). Investigating the Role of Teachers in Multicultural Lesson Planning from the Viewpoint of High School Teachers of Social Studies in Urmia, National Conference on Multicultural Education and Training, Iran Curriculum Studies Association, West Azerbaijan Province Unit.

Gheng, Y.C. (2004). Fostering local knowledge and human development in globalization of education International, Journal of Educational management, 18(1), 7-24.

Ghaderi, Mustafa (2008). The Discourses of Globalization and the Future of Curricula in Iran, the $8^{\text {th }}$ Conference of Curriculum Studies Association, Babolsar, Curriculum Studies Association.

Gall, Meredith; Bork, Walter \& Gall, Joyce (2013). Quantitative and Qualitative Research Methods, 1, Translated by Ahmad Reza Nasr et al. Tehran: Samt.

Ghasempour Dehaghani, Ali and Jafari, Seyed Ebrahim \& Liaghatdar, Mohammad Javad (2011). An Analysis on the Localization and Internationalization of the Curriculum of Universities in the Era of Globalization, Quarterly Journal of Cultural Researches, 4(4), 1-24.

Hamidizadeh, Katayoun, Fathi Vajjargah, Kourosh, Arefi, Mahboubeh \& Mehran, Golnar (2017). Multicultural Education: A Systematic Analysis of Teachers' Perception, Research Quarterly Journal of Teaching, 5(2), 1-16.

Huang, H. P., Cheng, Y. Y. \& Yang, C. F. (2017). Science teachers' perception on multicultural education literacy and curriculum practices, EURASIA Journal of Mathematics Science and Technology Education, 13(6), 2761-2775.

Jacob, M. M., Sabzalian, L., Jansen, J., Tobin, T. J., Vincent, C. G. \& LaChance, K. M. (2018). The Gift of Education: How Local Knowledge Can Transform the Future of Public Education, International Journal of Multicultural Education, 20(1), 157-185.

Jiafang, L. (2013). Curriculum Research in Mainland China, In Curriculum Innovations in Changing Societies, 85-103. Sense Publishers.

Kazempour, Ismail \& Ghaffari, Khalil (2009). Evaluation of the Curriculum Implemented in the Social Studies Course of High School Education, Theoretical Branch, Using the Robitaille'S Three-Dimensional Model, Quarterly Journal of a New Approach to Educational Management, 2(3), 89-108.

Kasteyeva, M. (2018). Belgium priority as a partner for the Republic of Kazakhstan. Opción, 34(85-2), 752-772.

Kolb, D. (1984). Experiential Learning, Englewood Cliffs, NJ. Prentice Hall.

Mansourian, Yazdan (2012). Seventy Practical Points in Designing and Conducting Qualitative Researches, Book of the Month of Generality, (176), 67-75.

Mohammadi, Shirkouh; Naghi Kamal Kharrazi, Seyed Ali; Kazemi Fard, Mohammad \& Pourkarim, Javad (2016). Providing a Model for Multicultural Education in Higher Education: Analyzing the Perspectives of Specialists of this Field in Iran, Research Teaching, 4(1), 65-91.

Matandare, M. A. (2018). Botswana Unemployment Rate Trends by Gender: Relative Analysis with Upper Middle Income Southern African Countries (2000-2016). Dutch Journal of Finance and Management, 2(2), 04.

Mulla, Somayeh \& Adib, Youssef (2017). Location-Based Education and Curriculum, First Conference on Why and How to Localize Curriculum, Publishing, 1(1).

Ministry of Education and Training (2010). National Document of Education and Training, the Philosophy of Formal and Public Training.

McCarthy, G. \& Stanton, C. R. (2017). Let His Voice Be Heard": A Community's Response to Inclusion of a Local Counter-Narrative in the District Curriculum, International Journal of Multicultural Education, 19(3), 1-22.

Misco, T. (2018). Culturally Responsive Curriculum and Pedagogy in the Commonwealth of the Northern Mariana Islands, International Journal of Multicultural Education, 20(2), 81-100. 
Muchenje, F. \& Heeralal, P. J. (2016). Teachers' Views on the Accommodation of Students' Cultural Diversity in Curriculum Instructional Materials in Use in Primary Schools in Chegutu District Zimbabwe, Journal of Social Sciences, 47(2), 142-150.

Offorma, G. C. (2016). Integrating Components of Culture in Curriculum Planning, International Journal of Curriculum and Instruction, 8(1), 1-8.

Osler, A. (2015). The stories we tell: Exploring narrative in education for justice and equality in multicultural contexts, Multicultural Education Review, 7(1-2), 12-25.

Parekh, B. (2008). The Concept of Multicultural Education. In S. Modgil, G. K. 18(1), 7-24.

Putnam, J. W., Putnam, D. E., Jerome, B. \& Jerome, R. (2011). Cross-cultural collaboration for locally developed local curriculum, International Journal of Multicultural Education, 13(2), 1-18.

Ramirez, P. C. \& Jaffee, A. T. (2016). culturally responsive active citizenship education for newcomer students: A cross-state case study of two teachers in Arizona and New York. International Journal of Multicultural Education, 18(1), 45-67.

Razaghi Robati, Afsaneh (2013). Study of the Findings and Experiences of Other Countries' Educational System about Multicultural Curriculum, National Conference on Multicultural Education and Training, Iran Curriculum Studies Association, West Azerbaijan Province Unit.

Sanders C. (2003). Application of Colaizzi's method: Interpretation of an auditable decision trail by a novice researcher, Contemp Nurse, 14(3), 292-302.

Sarraj, H., Bene, K., Li, J. \& Burley, H. (2015). Raising Cultural Awareness of Fifth-Grade Students through Multicultural Education: An Action Research Study. Multicultural Education, 22(2), 39-45.

Shawer, S. F. (2017). Teacher-driven curriculum development at the classroom level: Implications for curriculum, pedagogy and teacher training. Teaching and Teacher Education, 63, 296-313.

Sianturi, M., Chiang, C. L. \& Au Hurit, A. (2018). Impact of a Place-Based Education Curriculum on LocalTeacher and Students. International Journal of Instruction, 11(1), 311-328.

Spindler, G. D. (1987). Beth Anne: A Case Study of Culturally Defined Adjustment and Teacher Perceptions, In G. D. Spindler (Ed). Education and culture Process: Anthropological Approaches, 230-244. Prospect Heights, IL: Waveland Press.

Strauss, Anselm \& Corbin, Juliet (2011). Principles of Qualitative Research Method; Basic Theory of Procedures and Methods, Translation by Buick Mohammadi, Tehran: Research Institute of Humanities and Cultural Studies.

Sharif, Mustafa (2011). Curriculum, Discourse of Theory, Research and the Practice of Postmodern Curriculum, Isfahan: Publication of Jihad Daneshgahi.

Sadeghi, Alireza (2012). Characteristics and Necessities of Compiling Multicultural Curriculum in Iran; Challenges and Strategies, Scientific Research Quarterly Journal of the Strategy of Culture, 5(17, 18), 93-121.

Sadeghi, Alireza; Abdolmaleki, Saber \& Khodarahmi, Maryam (2017). Explaining the Localization of Teaching with Emphasis on the Role of Teacher, First Conference on Why and How to Localize Curriculum, Publishing, 1(1).

Tulgar, A. T. (2018). A case study on the effects of global second language setting on the language learning motivation of foreign learners of Turkish, International Journal of Multicultural Education, 20(3), 80-101. 